was easily got by cutting slits in two pieces of tinfoil with a razor and placing one over the other with the slits at right-angles, while for a triangular aperture three strips of tinfoil placed so as to leave just a tiny triangle open gave good results.

G. H. BRYAN.

The Secular Bending of Marble.

THE fluidity of marble under pressure, of which Dr. See mentions an instance in NA'ruRE (p. 56), has, I believe, been well established by laboratory experiments. Another instance of secular bending, similar to that quoted by Dr. See, was to be seen in two alabaster slabs which formed the jambs of a doorway in the Alhambra. Owing to the pressure brought to bear on these by the settlement of the building, they had bulged out from the wall by as much (if I remember right) as 6 or 7 inches. The slabs were about 7 feet long and a foot wide, their thickness being, perhaps, a couple of inches. Whether they are to be seen there still, or not, I do not know.

Spencer Pickering.

\section{Summer and Winter.}

CONCERNING the relation of summer and the following winter referred to on p. 63, a few facts from Greenwich records of the last sixty-one years may be acceptable. We find this :-

\begin{tabular}{|c|c|c|c|c|c|}
\hline & & & & & \\
\hline Summer & warm, & winter & severe, & 9 & cases. \\
\hline ," & cold & ", & $\begin{array}{l}\text { mild, } \\
\text { severe, }\end{array}$ & $\begin{array}{l}19 \\
17\end{array}$ & ", \\
\hline "3 & , & ," & mild, & 12 & , \\
\hline
\end{tabular}

(This leaves four cases with average values.)

It thus appears that warm summers have been distinctly more often followed by mild winters than by severe ones; but the difference in the other case, of cold summers, is less pronounced. In this representation, wet is left out of account, the mean temperatures of summer and winter being alnne considered, and in relation to the averages. But we might limit our attention to summers that have been both cold and wet, as this last summer has been. (Cold summers have not always an excess of rain.) Of such there appears to have been nineteen. Now taking all those with a mean temperature under $60^{\circ} \cdot 5$ (the average mean temperature of summer below $6 \mathrm{r}^{\circ} \cdot 2$ ), I find that nine were followed by severe winters and only three by mild winters; total, twelve. As the past summer comes in this group, the chances seem in favour of a severe winter. A. B. M.

\section{Personal.}

I DID not think it worth while to correct an error into which the reporters of the ephemeral Press fell in prefixing the words "his own" to the word "work" in the account of my recent speech at Liverpool, where I had said that my new sphere afforded me a larger opportunity for work : simply.

I do not know how best to correct it, or whether it is now possible, but I see it has been reproduced in your University Intelligence on p. 7O, and an error incorporated in NATURE is of rather permanent character, and may be misleading to my friends.

Birmingham, November $2 \mathrm{I}$.

\section{MATHEMATICS IN THE CAMBRIDGE

$$
\text { LOCALS. }
$$

N May 29 (vol.lxvi. p. I I7), we announced an important change in the geometry of the Oxford local examinations for 1903 . Quoting from the notice which had just been issued, attention was directed to the important statement that "Questions will be set so as to bring out as far as possible a knowledge of the principles of geometry, a smaller proportion than heretofore consisting of propositions as enunciated in Euclid. Any solution which shows an accurate method of geometrical reasoning will be accepted. No question will be set involving necessarily the use of angles greater than two right angles. Geometrical proofs of the theorems in Book ii. will not be insisted upon." We have now received the schedules in geometry that have been adopted for the Cambridge No. 1726 , VOL. 67$]$ preliminary and junior local examinations in 1903. In these, we are glad to see that the Cambridge Syndicate has adopted to an even greater extent the reforms suggested by the recent British Association Committee. For the preliminary, junior and senior examinations :"Any proof of a proposition will be accepted which appears to the examiners to form part of a logical order of treatment of the subject. In the proof of theorems and deductions from them, the use of hypothetical constructions is permitted." No schedule will be published for the senior examination. The importance of the schedules now published for the preliminary and junior examinations will be apparent when it is considered that they may be said to cover the work done by the boys and girls in all secondary schools up to the age of sixteen years, and the work of such older boys and girls as are not trying for marks of distinction. Their influence is great, and we heartily welcome the important change that they place much greater stress upon observation, measurement and experiment than on abstract reasoning. It is to be observed also that there is no mere pretence of accuracy:--"Every candidate must be provided with a ruler graduated in inches and tenths of an inch, and in centimetres and millimetres, a small set square, a protractor, compasses furnished with a hard pencil point, and a hard pencil." This mention of the hard pencil is business-like; as soon as boys understand that in their measurements of lines they must not make errors of even one-hundredth of an inch, their true scientific education begins. As for demonstrative geometry, a great number of Euclid's propositions are left out altogether. Books ii. and iv. have completely disappeared. Twenty-eight out of the forty-nine propositions of Book i. have to be studied for the preliminary and junior. Of the thirty-seven propositions of Book iii., only ten have to be studied for the preliminary and four more for the junior. Of the thirty-five propositions of Book vi., only thirteen are required for the junior. The most important part of the geometry examination is called practical geometry, and there is every inducement to all teachers now to dwell largely on experimental geometry, as all good teachers have done for many years.

We have reason to believe that in dealing with arithmetic, algebra and trigonometry, the syndicate will follow, as closely as it has done in geometry, the recommendations of the British Association Committee as drawn up by Prof. Forsyth. Should this be so, we are assured of a very great reform in the teaching of mathematics in all the secondary schools of England. This, consummation will be further assured by recognition of the reform, which will surely come soon, on the part of the Civil Service Commissioners and all other examining bodies in the kingdom. We may say, then, that every average boy looking forward to a career in the Civil Service, in the Navy, in the Army, in any of the professions, will have had an incubus lifted from his life, and a much greater load will have been lifted from the spirits of his father and mother. Boys susceptible of being crammed for examinations will no longer have an unfair advantage over their far wiser and more sensible but reputedly stupid fellow competitors. There will, moreover, be a chance that boys from schools will be able to take better and fuller advantage of the instruction given in technical colleges.

To the educationist, the reform, however far-reaching in its results, may appear small; he may think that it should have been effected long ago. This view, however, does not in our opinion do justice to the services of the reformers. It leaves out of account the strength of the opposition. This reform needed that many men should work in an unhopeful, heart-breaking way for it for many years, and its importance is not diminished by its coming 